\title{
The Growth of Pseudomonas phaseolicola and Related Plant Pathogens in vivo
}

\author{
By G. L. ERCOLANI* \\ Istituto di Patologia Vegetale, Universita degli Studi, Bologna, Italy \\ AND J. E. CROSSE \\ East Malling Research Station, Maidstone, Kent
}

(Received 24 March 1966)

\begin{abstract}
SUMMARY
In the leaves of their natural (homologous) hosts, the bean and cherry respectively, Pseudomonas phaseolicola and $\boldsymbol{P}$. morsprunorum increased logarithmically for at least 4 days after inoculation. Transition into the stationary phase was gradual and accompanied by water congestion of the infected tissues, followed by typical field symptoms. Increases in the inoculum dose had relatively little or no effect on the generation time but growth ceased earlier at the higher doses. In the reciprocal (heterologous) combinations, logarithmic growth was abruptly terminated after 2-3 days, due apparently to a specific defensive reaction in the host. This coincided at the higher inoculum doses with the appearance of dry necrotic symptoms in the leaves. No macroscopic symptoms were observed with the lower doses, and with the lowest dose in bean there was an acceleration of leaf maturation in the presence of heterologous organisms. Generation times were lower in heterologous combinations but increased markedly with the inoculum dose. The growth of the pear strain of $\boldsymbol{P}$. syringae in bean and cherry leaves showed typical heterologous characteristics. The final yields of bacteria per unit inoculum were invariably higher in homologous combinations, but they decreased with increasing dose, whereas heterologous yields increased. The differences in net growth response were therefore greatest at the lowest doses. This suggested that host specificity in the field was associated with factors controlling growth of the organisms in vivo from small initial inocula.
\end{abstract}

\section{INTRODUCTION}

The 'halo blight' organism Pseudomonas phaseolicola is virtually restricted in the field to species of the genus Phaseolus, whereas the related bacterial canker organism $\boldsymbol{P}$. morsprunorum is found only on plants of the genus Prunus. In common with many other phytopathogenic bacteria, however, both organisms when inoculated under suitable conditions will grow and induce symptoms in plants having little botanical affinity with their natural hosts (Erikson, 1945; Dye, 1958; Logan, 1960; Klement \& Lovrekovich, 1961, 1962; Klement, 1963; Klement, Farkas \& Lovrekovich, 1964). The following investigation compared the growth of $\boldsymbol{P}$. phaseolicola and $\boldsymbol{P}$. morsprunorum in natural hosts of these organisms and it was undertaken to

\footnotetext{
* Present address: Consiglio Nazionale delle Ricerche, Centro Sperimentale per la Sterilizzazione Industriale degli Alimenti, Parma, Italy.
} 
provide preliminary information on the factors determining host specificity in the field. A strain of $\boldsymbol{P}$. syringae from pear was also included in the investigation. This species was originally described from lilac but has since been identified in one form or another from thirty-nine different genera of host plants, including Phaseolus and Prunus. Pear strains of this organism are of a distinctive phage type apparently specific to this host in the field (Crosse \& Garrett, 1963).

\section{METHODS}

Test plants. These were seedlings of the dwarf bean Phaseolus vulgaris, varieties 'Enfant de Mont Calme' and 'Canadian Wonder', and 2-year-old potted sweet cherry trees, Prunus avium variety 'Bigarreau Moreau'. The beans were inoculated in the primary leaves before these were fully expanded and the cherries on the first fully expanded leaves on the extension shoots as soon as sufficient of these were available to ensure adequate replication.

Bacterial isolates. The isolate Pseudomonas phaseolicola 1L 3 was obtained from lesions on dwarf bean plants affected with halo blight in Italy in 1962. Pseudomonas morsprunorum was represented by a cherry strain, c 22 , originally isolated from leaf surfaces in Kent in 1960, and $P$. syringae by a pear strain, s 14, isolated from diseased blossoms in Sussex in 1959. Stock cultures of these organisms were maintained on nutrient agar $+2 \%(\mathrm{v} / \mathrm{v})$ glycerol slopes $(\mathrm{NAG})$ in half-ounce screwcapped bottles at approximately $4^{\circ}$.

Preparation of inoculum. A $24 \mathrm{hr}$ growth on a NAG slope was quickly suspended in $5 \mathrm{ml}$. of sterile distilled water and immediately decanted into a sterile test tube. From this suspension a series of inocula at $10^{7}, 10^{6}, 10^{5}$ and $10^{3}$ bacteria $/ \mathrm{ml}$. was prepared, the concentration being adjusted turbidimetrically by reference to calibration curves relating extinction to numbers of viable organisms (colony counts).

Inoculation techniques. Suspensions were infiltrated through the stomata on the lower surface of the leaves by applying them in the form of fine spray delivered from a paint gun supplied with compressed air $\left(25 \mathrm{lb} . / \mathrm{in} .{ }^{2}\right)$, and held at about $6 \mathrm{~cm}$. from the leaf surface. Infiltrated areas became dark green due to water congestion of the intercellular spaces, but this disappeared after 2-3 hr. leaving no visible signs of damage to the tissues. Subsequent symptom patterns invariably showed the bacteria to have been fairly uniformly distributed in the leaves, except for narrow bands of tissues running along the main veins which were rarely penetrated. On each host each treatment, i.e. bacterium/concentration combination, was applied to a separate group of plants, the number of plants in each group being sufficient to provide 20 leaves of comparable age and size for inoculation. This degree of replication and the systematic sampling procedure described below were found to be essential for obtaining growth curves of acceptable accuracy and reproducibility. After inoculation the test plants were maintained in an air-conditioned greenhouse at $20-25^{\circ}$.

Estimation of bacterial populations in the leaves. Four hours after inoculation the leaves were thoroughly rinsed in sterile distilled water to remove as many as possible. of the bacteria adhering to the surfaces. The first sample of leaf tissue was then taken for estimation of bacterial numbers and the sampling repeated daily for $\mathbf{5}$ days, and in some instances on the seventh and tenth days after inoculation. On each sampling occasion three $5 \mathrm{~mm}$. discs of tissue were cut from each of the 20 leaves under each 
treatment, from sites between the main veins defined in advance on a systematic pattern. The sixty discs/treatment thus obtained were bulked, washed in two changes of sterile distilled water and homogenized in $12 \mathrm{ml}$. of sterile distilled water (SDW) for $4 \mathrm{~min}$. in an MSE microhomogenizer running at $12,000 \mathrm{rev} \cdot / \mathrm{min}$. With cherry leaves a phosphate buffer was added before homogenizing. The homogenates were allowed to stand for $1 \mathrm{hr}$ with intermittent shaking.

A series of dilutions was then prepared from the supernatant fluids and $1 \mathrm{ml}$. samples of these spun in Astell roll tubes with $4.5 \mathrm{ml}$. of molten $\left(48^{\circ}\right)$ nutrient agar containing $5 \%(\mathrm{w} / \mathrm{v})$ sucrose and 1/124,000 crystal violet (British Drug Houses). In this medium Pseudomonas phaseolicola, $P$. morsprunorum and $P$. syringae all form characteristic radially-striated levan-type colonies (Crosse, 1959) which are readily distinguishable from colonies of contaminant organisms, although in practice the latter were rarely encountered.

Colony counts were made after 3 days at $25^{\circ}$ and from these the numbers of bacteria $/ \mathrm{cm} .^{2}$ leaf tissue were calculated.

\section{RESULTS}

Three separate comparisons were made with each organism in bean and two in cherry. For simplicity, general growth trends in leaves are illustrated by the results of a single experiment in each host (Fig. 2). For all other purposes the results of replicate experiments were combined. This was justified by the high degree of reproducibility obtained. The initial inoculum dose (n 4 ) in each treatment was taken as the number of bacteria/cm. ${ }^{2}$ leaf recovered at $4 \mathrm{hr}$. Mean generation times (m.g.t.) were calculated from values interpolated from the growth curves near the beginning and the end of the logarithmic phase. Final populations $/ \mathrm{cm} .^{2}$ leaf in the stationary phase (n.s.p.) were estimated by extrapolating parallel to the time axis to time 0. To obtain a measure of the period of active population increase in the leaves, the growth period, we calculated the time $(t)$ that would have been required to reach the stationary phase in a state of continuous logarithmic growth.

It was assumed in this work that the numbers of bacteria recovered from leaves were always a constant proportion of the numbers actually present. This was confirmed by plotting log. $\mathrm{n} 4$ against the log. inoculum concentration. The two were linearly related (Fig. 1), showing that for a tenfold increase in the numbers of bacteria infiltrated in the leaves, there was a tenfold increase in the numbers recovered.

\section{General growth characteristics in vivo}

Population trends. The relationship between numbers of bacteria $/ \mathrm{cm} .{ }^{2}$ leaf and time is shown in Fig. 2. In no bacterium/host combination was there evidence of a lag phase beyond $4 \mathrm{hr}$ except with Pseudomonas morsprunorum in cherry, where it was extended to between 4 and $24 \mathrm{hr}$. In all cases the populations increased logarithmically and with the homologous combinations, i.e. $P$. phaseolicola in bean and $P$. morsprunorum in cherry, entered into a stable stationary phase after about 5 days. With the heterologous combinations the transition was more abrupt and occurred earlier, usually between 2 and $\mathbf{3}$ days. The only significant departure from this pattern occurred with $P$. syringae at the highest inoculum dose in cherry. Here the maximum populations were attained at a very early stage, but these then declined 
to a stable level below the stationary phase of the next lowest inoculum concentration.

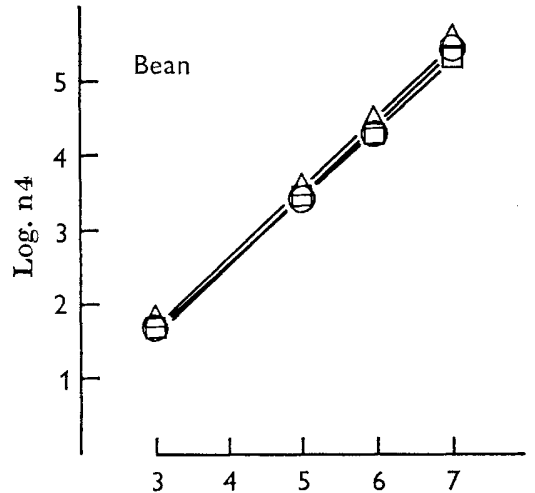

Log. inoculum concentration

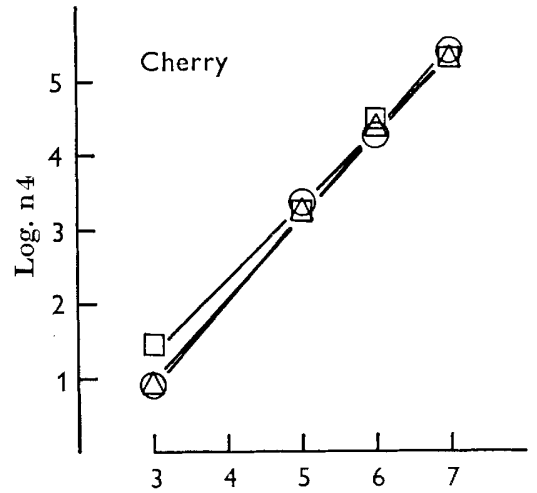

Log. inoculum concentration

Fig. 1. Relationship between inoculum concentration and initial inoculum dose (n4) in bean and cherry leaves. Pseudomonas phaseolicola (O), P. morsprunorum ( $\square$ ) and $P$. syringae $(\triangle)$.

Rate of growth. The mean generation times in the logarithmic phase varied between 5 and $6 \mathrm{hr}$ for homologous bacteria and between 5 and $13 \mathrm{hr}$ for the heterologous forms, according to the initial inoculum dose (Table 1). These values compare with generation times for these organisms of 1-2 hr under optimal conditions in vitro. The rate of growth (generations/hr) of the homologous bacteria was generally higher than that of the heterologous bacteria, but it increased less rapidly with the inoculum dose (Fig. 3). The differences were therefore less marked with the higher doses. In one of the homologous combinations, Pseudomonas morsprunorum in cherry, the rate of growth was more or less independent of the inoculum size. The rate of growth of the heterologous organisms increased approximately linearly with $\log$. $n 4$ except for $\boldsymbol{P}$. syringae in cherry, where there was an abnormal increase in the growth rate at the highest inoculum dose to a value above that of the corresponding

Table 1. Mean generation times of Pseudomonas phaseolicola, $\boldsymbol{P}$. morsprunorum and $\boldsymbol{P}$. syringae in bean and cherry leaves

\begin{tabular}{|c|c|c|c|}
\hline \multirow[b]{2}{*}{ Pathogen } & \multirow{2}{*}{$\begin{array}{c}\text { Inoculum } \\
\text { concentration }\end{array}$} & \multicolumn{2}{|c|}{ Mean generation time (hr) : } \\
\hline & & in bean & in cherry \\
\hline \multirow[t]{4}{*}{ P. phaseolicola } & $10^{3}$ & $5 \cdot 48 *$ & $13 \cdot 32$ \\
\hline & $10^{5}$ & $5 \cdot 32 *$ & $9 \cdot 07$ \\
\hline & $10^{6}$ & $5 \cdot 05^{*}$ & $7 \cdot 93$ \\
\hline & $10^{7}$ & $4.78 *$ & $6 \cdot 93$ \\
\hline \multirow[t]{4}{*}{ P. morsprunorum } & $10^{3}$ & $13 \cdot 28$ & $6 \cdot 23^{*}$ \\
\hline & $10^{5}$ & $9 \cdot 60$ & $6 \cdot 18^{*}$ \\
\hline & $10^{6}$ & $7 \cdot 97$ & $6 \cdot 43^{*}$ \\
\hline & $10^{7}$ & $6 \cdot 83$ & $6 \cdot 13 *$ \\
\hline \multirow[t]{4}{*}{ P. syringae } & $10^{3}$ & $13 \cdot 13$ & $9 \cdot 08$ \\
\hline & $10^{5}$ & $7 \cdot 95$ & $7 \cdot 43$ \\
\hline & $10^{6}$ & $6 \cdot 32$ & $6 \cdot 78$ \\
\hline & $10^{7}$ & $5 \cdot 25$ & $5 \cdot 28$ \\
\hline
\end{tabular}

* Homologous combinations. 

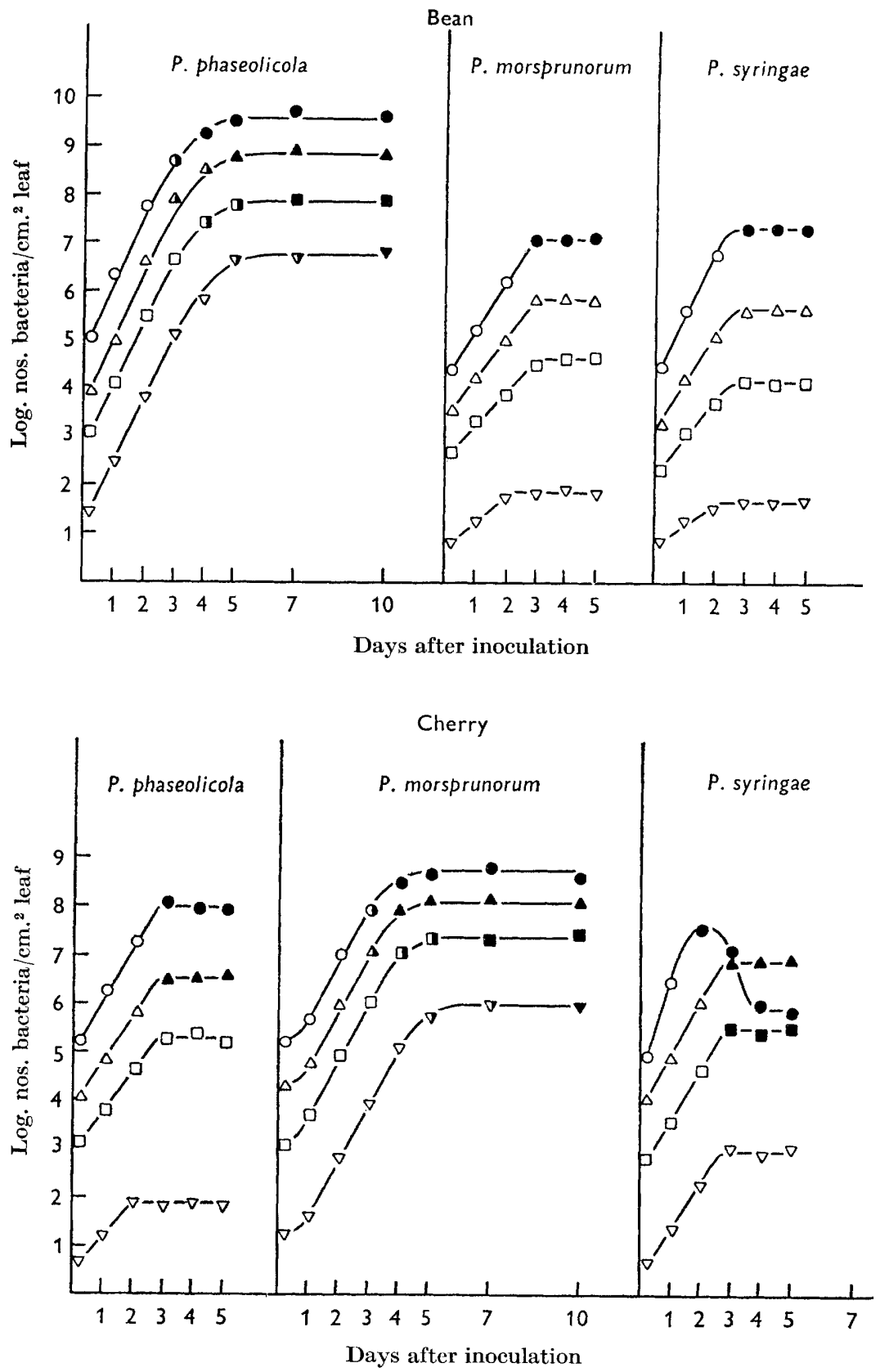

Fig. 2. Log. nos. bacteria in bean and cherry leaves at various intervals after inoculation. Inoculum concentrations (bacteria $/ \mathrm{ml}$.) $: 10^{3}(\nabla), 10^{5}(\square), 10^{6}(\triangle), 10^{7}(\bigcirc)$. Half-closed symbols indicate first appearance of water soaking in tissues and closed symbols first appearance of necrotic symptoms. 
homologous organism. This was observed in duplicate experiments and in both cases it was associated with early inhibition of logarithmic growth followed by a decline in populations.

Growth periods. These varied from about 100 to $70 \mathrm{hr}$ for homologous bacteria, and from about 69 to $43 \mathrm{hr}$ for heterologous bacteria, according to the size of the initial inoculum dose. In homologous combinations the growth period, $t$, decreased fairly regularly as the dose was raised, but there was no consistent relationship between $t$ and dose in the heterologous combinations (Fig. 4). Thus in three heterologous combinations the shortest growth period occurred at the lowest dose; there was a marked extension of the growth period at the next dose, but further increase in the dose had either no effect (Pseudomonas phaseolicola in cherry) or decreased the growth period only fractionally ( $P$. syringae and $P$. morsprunorum in bean). In the
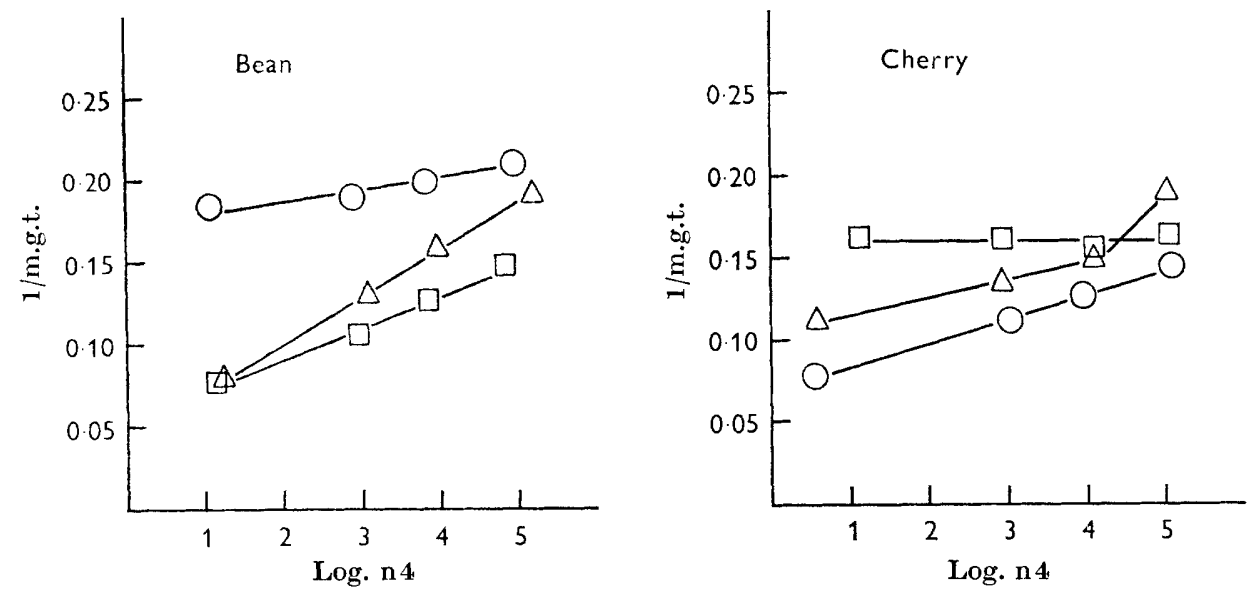

Fig. 3. Mean no. generations $/$ hr (1/m.g.t.) in the logarithmic phase of Pseudomonas phaseolicola $(O), P$. morsprunorum $(\square)$ and $\boldsymbol{P}$. syringae $(\triangle)$ after inoculation at various inoculum doses $(\mathrm{n} 4)$ into bean and cherry leaves.
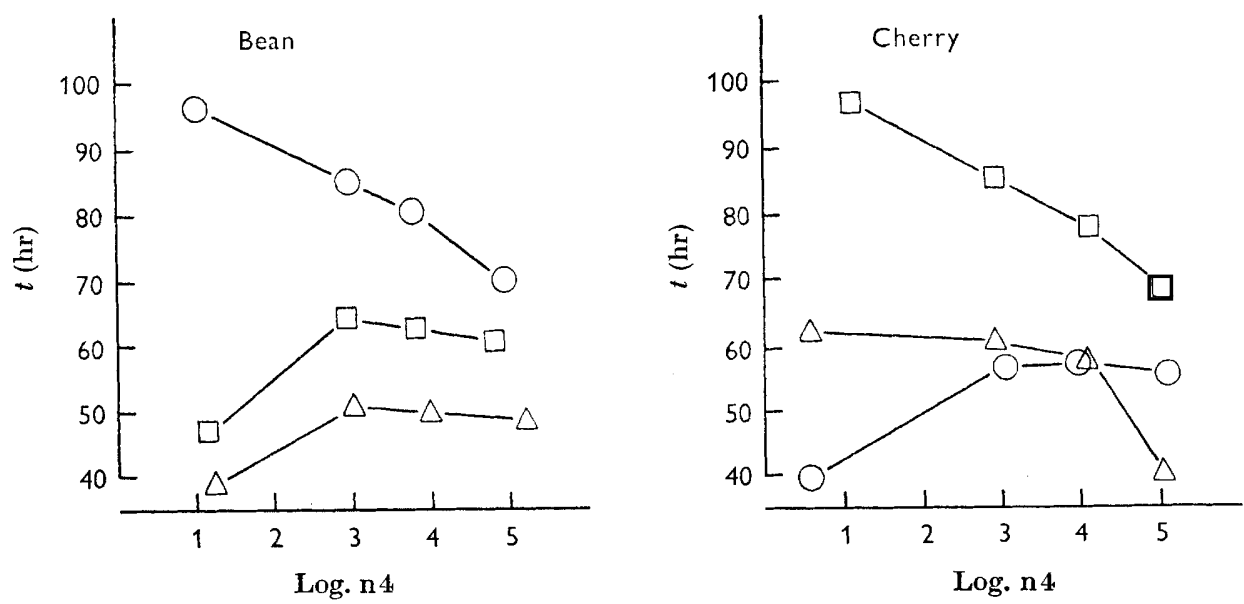

Fig. 4. Effect of inoculum dose (n4) on the growth period $(t)$. Pseudomonas phaseolicola (O), P. morsprunorum $(\square)$ and $P$. syringae $(\triangle)$. 
fourth combination ( $\boldsymbol{P}$. syringae in cherry) the situation was reversed, the longest growth period occurring at the lowest dose; increase in the dose had little effect except at the highest dose when there was a significant shortening of the growth period.

The abrupt termination of heterologous growth has been noted by other investigators and attributed to a specific inhibitory reaction in the host (Allington \& Chamberlain, 1949; Klement \& Lovrekovich, 1962; Klement et al. 1964). Its occurrence in bean and cherry leaves was completely unrelated to the concentration of bacteria in the tissues at the time. For example, the final populations (n.s.p.) at the end of the logarithmic phase of $\boldsymbol{P}$. phaseolicola in cherry at the lowest dose were $4.3 \times 10 / \mathrm{cm}^{2}$ leaf tissue, and at the higher doses $1.2 \times 10^{5}, 2.2 \times 10^{6}$ and $5.7 \times$ $10^{7} / \mathrm{cm}^{2}$, respectively. The corresponding values of $t$ were $44,61,61$ and $60 \mathrm{hr}$, respectively.
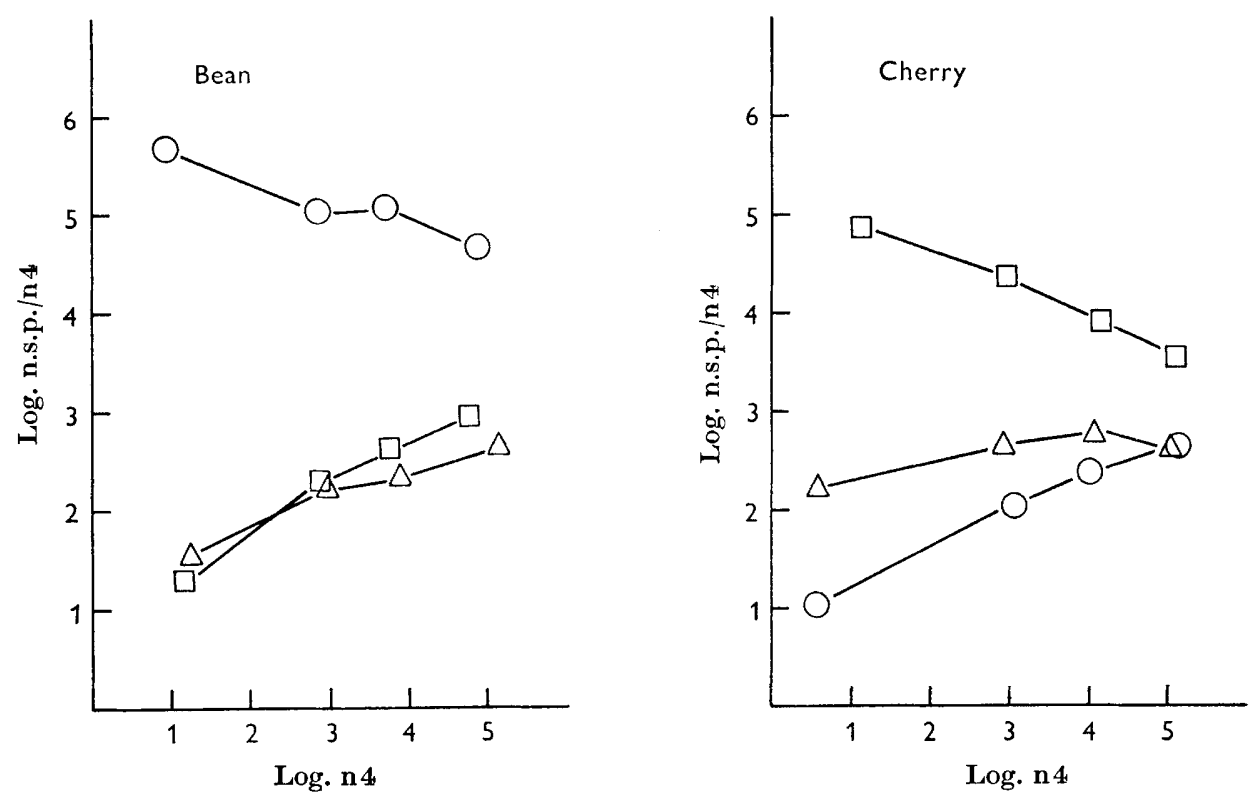

Fig. 5. Effect of inoculum dose (n4) on the final yield of bacteria per unit inoculum (n.s.p./n 4). Pseudomonas phaseolicola $(\bigcirc), P$. morsprunorum $(\square)$ and $P$. syringae $(\triangle)$.

Growth yields. The yield per unit inoculum (n.s.p./n4) of the bacteria in homologous and heterologous combination is shown in Fig. 5. This summarizes the net growth response of the organisms at different doses. The most striking feature was that the yield of heterologous bacteria increased with dose while that of the homologous bacteria decreased. The difference in relative efficiency with which the leaf substrate was utilized for growth was thus most marked at the lower doses. The magnitude of the difference is illustrated by the yields per unit inoculum of Pseudomonas phaseolicola and $\boldsymbol{P}$. morsprunorum in bean. These were $4.4 \times 10^{5}$ and $1.9 \times 10$, respectively, at the lowest dose; $4.7 \times 10^{4}$ and $9.3 \times 10^{2}$ at the highest dose. The homologous/heterologous productivity ratios, i.e. relative yields, for these particular combinations were therefore approximately 232,000:1 at the lowest dose, but only $51: 1$ at the highest dose. 
Since the growth rates of homologous bacteria were not markedly affected by the dose size, the yields at different doses were primarily determined by the length of the growth period. The yield of heterologous bacteria, on the other hand was primarily determined by the growth rate, except occasionally at extreme doses where there was an effect of dose on the growth period.

\section{Symptom development}

Mature symptoms consisted of brown and desiccated necrotic areas in the interveinal regions of the leaf. With heterologous bacteria they were produced after 2-3 days and approximately coincided with the abrupt transition from logarithmic to stationary growth (closed symbols in Fig. 2). The incubation period was longer with homologous bacteria and the mature symptoms were always preceded by the
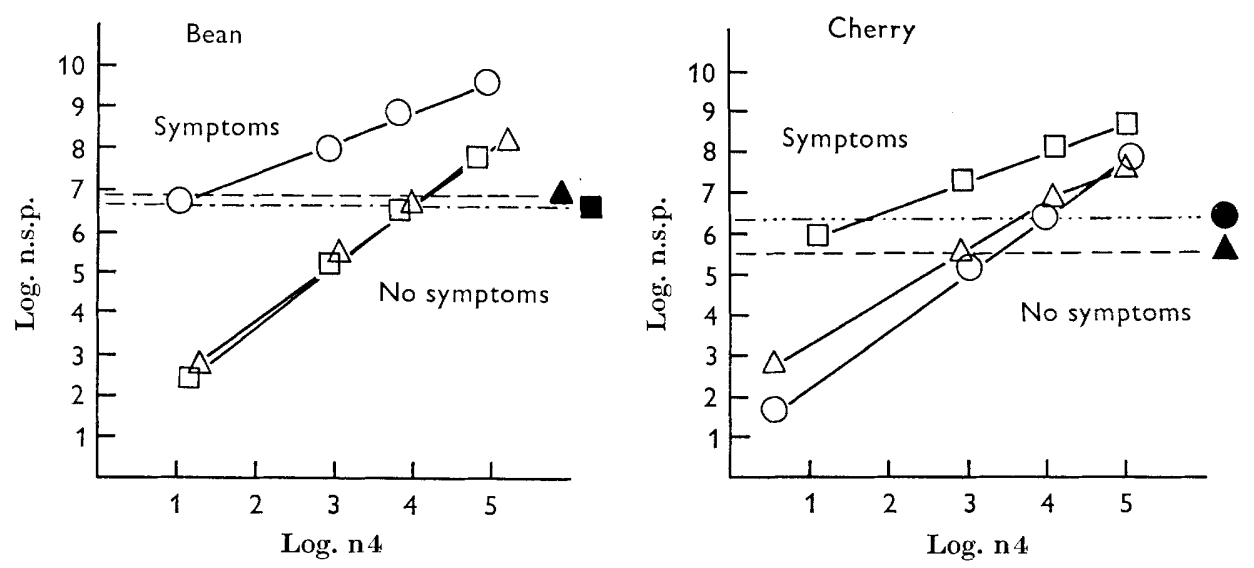

Fig. 6. Relationship between symptom production, final bacterial populations $/ \mathrm{cm}^{2}$ leaf in the stationary phase (n.s.p.), and the inoculum dose (n4). Pseudomonas phaseolicola ( $\bigcirc), \boldsymbol{P}$. morsprunorum $(\square)$ and $\boldsymbol{P}$. syringae $(\triangle)$. Closed symbols indicate minimum final populations for symptom production in heterologous bacterium/host combinations.

development of olive-green water-soaked areas in the affected tissues during the transition period of growth (half-closed symbols in Fig. 2). The total time for production of mature symptoms of homologous bacteria varied from 4 days at the highest inoculum dose to between 7 and 10 days at the lowest dose. The latter resulted in discrete circular spots reminiscent of field infection. At higher doses the spots became confluent and large continuous areas of tissues were destroyed. Confluent necrosis was observed only with heterologous bacteria at the highest inoculum dose; there were no symptoms at the lower doses. These differences were related to the concentration of bacteria in the stationary phase (n.s.p.; Fig. 6). The broken horizontal lines in Fig. 6 indicate the lowest values of n.s.p. observed in the experiments for symptom production by an heterologous organism. The minimum value was always exceeded by homologous bacteria but by the heterologous organisms only at the higher inoculum doses. 


\section{Effect of in vivo growth on the expansion of primary leaves}

The introduction of pathogenic bacteria into the intercellular spaces of immature leaves usually resulted in a visible check to further leaf expansion as compared with the uninoculated controls. Exceptions to this occurred with the lowest concentrations of the heterologous organisms, Pseudomonas morsprunorum and $\boldsymbol{P}$. syringae in bean, where there was evidence of stimulatory effect. This is illustrated in Fig. 7, which shows the percentage increase or decrease in leaf area (maximum length $x$ maximum width) as compared with controls when the primary leaves of bean plants were inoculated with different concentrations of the heterologous or ganism. The results for duplicate plants are shown separately and the values are the means for the two primary leaves on each plant.
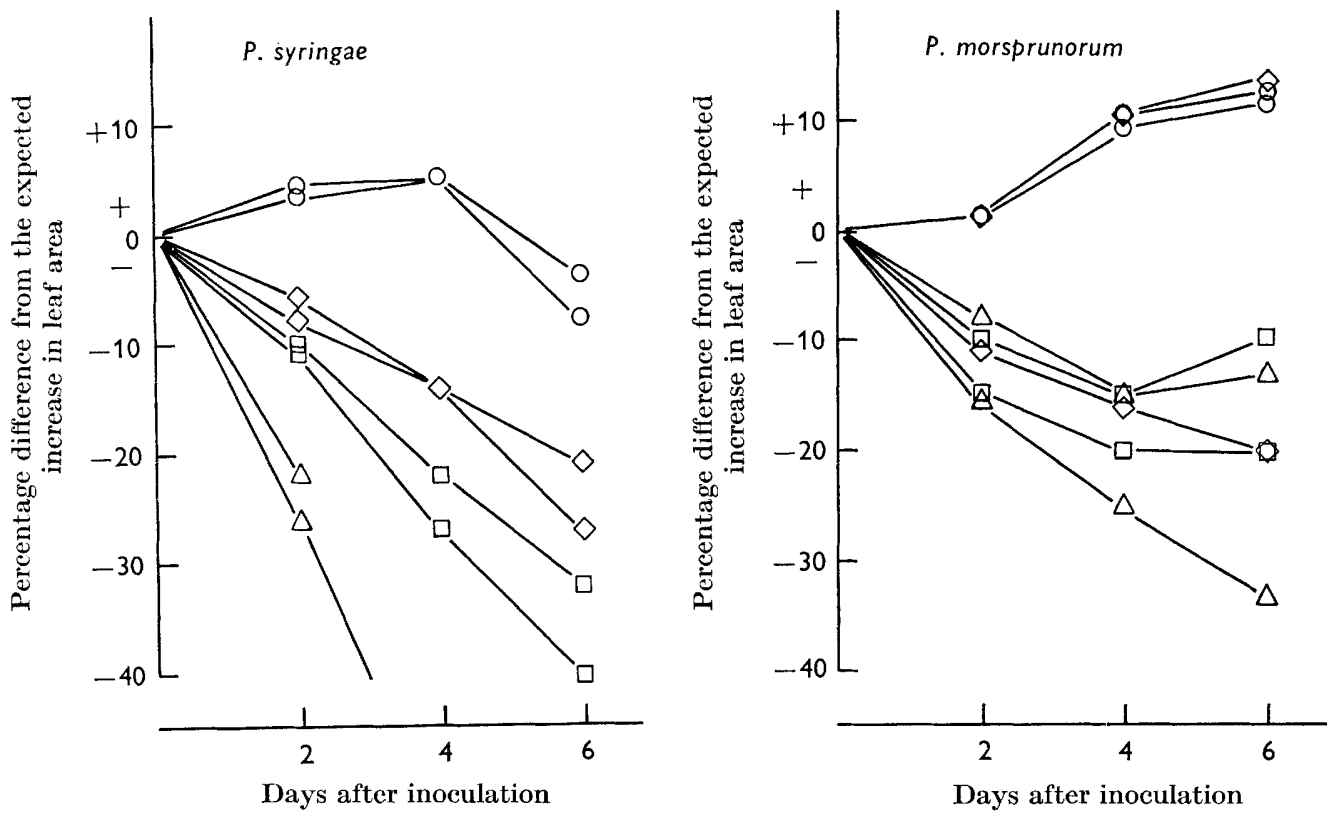

Fig. 7. Effect of heterologous organisms Pseudomonas syringae and $P$. morsprunorum at various inoculum concentrations on the expansion of primary leaves of bean. Inoculum concentrations (bacteria $/ \mathrm{ml}$.): $10^{3}(\bigcirc), 10^{5}(\diamond), 10^{6}(\square), 10^{7}(\triangle)$.

The most striking effect was with the lowest concentration of Pseudomonas morsprunorum where the relative area of the leaves increased progressively during the first 6 days after inoculation by $>10 \%$ over that of the uninoculated controls. A similar effect was observed in one duplicate plant at $10^{5}$ bacteria $/ \mathrm{ml}$., but in the other replicate there was a depression of leaf growth. With $P$. syringae, the stimulatory effect at the lowest inoculum concentration persisted for 4 days, after which the effect was reversed and the final leaf area was slightly less than the controls. At all other inoculum concentrations intercellular growth of $\boldsymbol{P}$. syringae and $\boldsymbol{P}$. morsprunorum checked or retarded leaf expansion to a degree related to the inoculum concentrations. 


\section{DISCUSSION}

The abrupt termination of the logarithmic growth phase of heterologous pseudomonas organisms in bean and cherry leaves agreed with results of other workers and must be similarly attributed to specific bacteriostatic responses induced in the host (Allington \& Chamberlain, 1949; Klement \& Lovrekovich, 1961, 1962). Whether it was the same as the hypersensitivity reaction described by Klement et al. (1964) in tobacco leaves is less certain, since it was not accompanied at the lowest inoculum doses by visible necrosis of the leaf tissues. Necrosis may have occurred at the cell level and was not detected at the surface of the leaves. It is difficult, however, to reconcile damage to the tissues with the increased rate of maturation which followed the introduction of heterologous bacteria into bean leaves at the lowest inoculum concentration.

The lack of relationship between the time of appearance of the inhibitory response and the initial and final bacterial populations in the leaves also agrees with results in other heterologous combinations (Klement \& Lovrekovich, 1961, 1962; Klement et al. 1964) and it suggests that induction of the response may be largely independent of the numbers of bacteria in the tissues. This is consistent with recent evidence which indicates that induction occurs soon after inoculation and is followed by a latent period before the inhibitory effect appears (Klement \& Goodman, personal communication). Except in a few instances at extreme doses the inhibitory effect in bean and cherry leaves appeared at a relatively constant interval after inoculation. This could be explained by postulating that the length of the latent period is primarily determined by host reactions which proceed after induction independently of bacterial growth. However, it is clear that additional factors were operating at the extreme doses. At the lowest inoculum dose in bean one such factor may have been the more rapid maturation of the leaves. The physiological changes associated with this process are well known to increase the resistance of tissues to pathogenic bacteria ('mature-leaf resistance'). Possibly this accelerates or shortcircuits host reactions during the latent period.

The lower growth rate of heterologous bacteria in the logarithmic phase compared with homologous forms has not been previously reported. In bean and cherry leaves it was apparent soon after inoculation and hence, if due to plant inhibitors, these were either induced very rapidly, or were present before infection. It is worth noting in this connexion that Klement \& Lovrekovich (1962) postulated the presence of pre-infection inhibitors to explain the failure of the saprophytic pseudomonas species to grow in plant tissues. Alternatively the slower growth of the heterologous forms may have been due to their inability to mobilise adequate leaf nutrients. Bacterial growth is predominantly intercellular but depends ultimately on the extent to which mesophyll cells of the plant can be rendered permeable to intracellular nutrients. The water soaking of tissues which invariably preceded the production of necrotic symptoms by homologous pseudomonads indicated drastic changes in cell permeability in the presence of these organisms. There was no evidence of a comparable effect in the presence of heterologous pseudomonads.

The growth of homologous organisms approximated more closely to growth in vitro and there were no signs in the growth curves of any inhibitory host reaction comparable to that induced by the heterologous forms. They also differed from the heterologous forms by producing progressively lower yields per unit inoculum with 
each successive dose increase. This was primarily due to the shortening of the logarithmic phase and not to changes in the generation time. Thus the growth of homologous bacteria was not markedly affected until they had reached relatively high concentrations in the tissues, when it is probable that they begin to compete for a dwindling supply of leaf nutrients. The shorter logarithmic periods at the higher doses, therefore, may simply reflect the attainment of nutritionally competitive population levels at an earlier stage than at the lower doses.

At all inoculum doses homologous organisms grew more efficiently than heterologous forms, but the difference was greatest at the lowest inoculum dose, and there is little doubt that it would have been even greater if the inoculum dose had been reduced even further. There are strong implications here that host specificity in the field may be related to factors controlling in vivo growth of these organisms from very small inocula. In the field the stone fruit pathogen, Pseudomonas morsprunorum, occurs as an epiphyte on the leaves of its host (Crosse, 1959) and is mobilized in rain to give inoculum which Shanmuganathan (1962) has estimated to vary between $10^{2}$ and $10^{5}$ bacteria/ml. under optimal disease conditions. This is the same order of concentration as the lowest experimental inocula. In the experiments, however, inoculum was infiltrated into leaves until all the intercellular spaces were filled and the leaves visibly water-congested. Penetration never occurs on this scale in the field, so that the actual inoculum dose in natural infection can only be a fraction of those used here experimentally. At these concentrations, it is clear that heterologous organisms would not induce disease symptoms. Indeed it is doubtful whether they would grow in leaves at all. Further information is required on the minimum effective dose for in vivo growth. In the meantime extrapolation from the present results suggests that wheras this may be very low for homologous organisms, considerably higher numbers of bacteria would be required to initiate in vivo growth of heterologous organisms.

\section{REFERENCES}

Allington, W. B. \& Chamberlain, D. W. (1949). Trends in the population of pathogenic bacteria within the leaf tissues of susceptible and immune plant species. Phytopathology 39, 656 .

Crosse, J. E. (1959). Bacterial canker of stone-fruits. IV. Investigation of a method for measuring the inoculum potential of cherry trees. Ann. appl. Biol. 47, 306.

Crosse, J. E. \& Garrett, C. M. E. (1963). Studies on the bacteriophagy of Pseudomonas mors-prunorum, $P$. syringae and related organisms. J. appl. Bact. 26, 159.

Dye, D. W. (1958). Host specificity in Xanthomonas. Nature, Lond. 182, 1813.

Erikson, D. (1945). Certain aspects of resistance of plum trees to bacterial canker. II. On the nature of bacterial invasion of Prunus sp. by Pseudomonas mors-prunorum Wormald. Ann. appl. Biol. 32, 112.

KLEMENT, Z. (1963). Rapid detection of the pathogenicity of phytopathogenic pseudomonads. Nature, Lond. 199, 299.

Klement, Z. \& Lovrekovich, L. (1961). Defence reactions induced by phytopathogenic bacteria in bean pods. Phytopath. Z. 41, 217.

Klement, Z. \& Lovrekovich, L. (1962). Studies on host-parasite relations in bean pods infected with bacteria. Phytopath. Z. 45, 81.

Klement, Z., Farkas, G. L. \& Lovrekovich, L. (1964). Hypersensitive reaction induced by phytopathogenic bacteria in the tobacco leaf. Phytopathology 54,474 .

Logan, C. (1960). Host specificity of two Xanthomonas species. Nature, Lond. 188, 479.

Shanmuganathan, N. (1962), Studies in bacterial canker of plum and cherry (Pseudomonas mors-prunorum Wormald). Ph.D. Thesis. University of London. 